\title{
CSAE WPS/2003-15
}

\section{Public Service Provision, User Fees, and Political Turmoil*}

\author{
Marcel Fafchamps \\ Bart Minten \\ University of Oxford ${ }^{\dagger}$ \\ Cornell University
}

September 2003

\begin{abstract}
Following an electoral dispute, the central highlands of the island of Madagascar were subjected to an economic blockade during the first half of 2002. After the blockade ended in June 2002, user fees for health services and school fees were progressively eliminated. This paper examines the provision of schooling and health services to rural areas of Madagascar before, during, and after the blockade. We find that public services were more resilient to the blockade than initially anticipated, but that health services were more affected than schools. The removal of user fees had a large significant effect on public services that is distinct from the end of the blockade and the increase in school book provision.
\end{abstract}

\footnotetext{
${ }^{*}$ We are grateful to Peter Glick and Mead Over for their useful comments and suggestions. We would like to thank USAID for the funding of this research through the cooperative agreement with Cornell University no 687-00-00-00093-00. We would further like to thank Eliane Ralison, Lalaina Randrianarison, Milasoa Cherel-Robson and Nathalie Francken for help with the set-up of the surveys as well as with the interpretation of the results.

${ }^{\dagger}$ Department of Economics, University of Oxford, Manor Road, Oxford OX1 3UQ. Email: marcel.fafchamps@economics.ox.ac.uk. Fax: +44(0)1865-281447. Tel: +44(0)1865-281446.

${ }^{\ddagger}$ Cornell Food and Nutrition Policy Program, Cornell University, BP 6317, Antananarivo 101, e-mail: bminten@dts.mg.
} 


\section{Introduction}

Providing public services such as basic health and education to millions of poor people all over the world is one of the fundamental challenges of this century. Yet little is known regarding the factors affecting the supply and demand for these services in poor countries. One issue that has been debated in the recent literature is the effect of user fees on demand for health and education (e.g. Pradhan \& Prescott 2002, Deininger 2003, Alderman, Orazem \& Paterno 2001, Gertler \& Glewwe 1990, Behrman \& Knowles 1999). Lack of funding is a major cause for insufficient provision of public services in less developed countries. Cost recovery in the form of user fees is seen by many as a way of easing funding constraints, and thereby of increasing supply. Although the importance of adequate funding is not in dispute, some researchers worry about the effect user fees have on demand, especially among the poor.

Using data from a natural experiment, this paper shows that user fees have a significant effect on the provision of health and education. We also examines the effect that political shocks have on social services. Poor countries are often subjected to riots, blockades, and various forms of warfare. These political shocks are likely to disrupt the delivery of public services but there is little evidence regarding the magnitude of the disruption. In particular, it is not known which public services are more resilient and which are more vulnerable. This paper provides evidence suggesting considerable resilience in primary and secondary education but much more vulnerability in health care delivery.

The data on the basis of which this paper is written comes from Madagascar, an island with a population of approximately 16 million people off the East coast of Africa. In the first half of 2002, Madagascar experienced a major political crisis. This crisis was the outcome of a dispute over the results of a presidential election held in December 2001. The incumbent presidential candidate decided to blockade the central highlands of the country for several months. The blockade, which lasted from January to June 2002, affected the delivery of public services in several ways. Essential supplies became scarce, especially drugs and medical equipment (Programme Ilo 2002b). Fuel prices experienced a six-fold increase in the central highlands. Energy generation and distribution were also disrupted and poverty increased dramatically (Fafchamps \& Minten 2002). Fortunately, violent confrontation between the two 
sides of the political dispute remained limited and little bloodshed occurred. ${ }^{1}$

The aftermath of the crisis also introduced massive changes in public service delivery. As a palliative to the massive increase in poverty generated by the blockade, the new president ordered in August and September 2002 a (temporary) elimination of health care and school fees. These measures were not adopted simultaneously in all provinces but rather followed the gradual process of reestablishment of central authority over the country. By June 2003 - one year later - all provinces had eliminated school fees and user fees in health care (e.g. Programme Ilo 2003b, Programme Ilo 2003a).

The blockade and the subsequent removal of user fees provides a natural experiment from which to examine the resilience of public services to massive shocks and the effect of a removal of user fees on public service provision. Data on public service provision were collected immediately before the crisis in December 2001, at the height of the blockade in June 2001, and during the period of gradual removal of user fees in November 2002. Collecting data during the blockade put the resourcefulness of our experienced enumerators to the test as they had to operate in difficult logistical circumstances. These data give us a rare glimpse into the workings of public service provision under stress.

What makes this paper unique is the fact that these massive changes took place over a very short time period. Over this short period, location-specific factors affecting the demand and supply of public services can be regarded as constant - and can be controlled for using fixed effects. Under normal conditions, short panels convey little information because changes occurring over a short period are typically small in magnitude. As a result, measurement error weakens econometric results. This is less true in our case.

The paper is organized as follows. We begin in Section 2 with a short historical account of the political crisis that sets the stage for this paper. A simple conceptual framework is introduced in Section 3. The data are presented in Section 4. Descriptive and qualitative evidence is discussed in Section 5. Econometric results are presented in Section 6 for the education and health sectors. Conclusions and policy implications are presented at the end.

\footnotetext{
${ }^{1}$ Violent confrontation between partisans of the two sides took place nearly exclusively in June 2002 , shortly before the end of the crisis. Approximately 100 casualties were reported in various incidents. The crisis was ended in late June with the departure from the country of the incumbent presidential candidate.
} 


\section{The Political Crisis}

The political crisis that sets the stage for our analysis unfolded in Madagascar as a result of the first round of the presidential election held in December 2001. The official count did not identify a clear winner in the first round as the incumbent president (Ratsiraka) was shown to obtain $42 \%$ of the votes compared to $46 \%$ of the votes for the opposition leader (Ravalomanana). However, the own polling results of the opposition leader as well as the results of a donor funded election monitoring committee showed that the opposition leader gathered enough votes $(>50 \%)$ in the first round to be declared the winner. ${ }^{2}$ Hence, the opposition leader maintained that election results were rigged.

Major strikes were organized in anticipation of the official results and in contestation of the official results as soon as they came out. Thousands of people gathered every day in the capital of Antananarivo to show their support to the opposition leader. Most of these strikes took place in the capital, the stronghold of the opposition leader, as he was the popular mayor of the capital just before the elections and as he belongs to the Merina tribe that lives in the highlands in and around the capital. After a month of standoff and under popular pressure to move ahead, the opposition leader declared himself president, formed his own government, and took hold of the ministries in the capital.

The incumbent president Ratsiraka did not accept this turn of events and insisted on a second round arguing that none of the two candidates obtained the required $50 \%$ of the votes. With the support of governors he had earlier appointed in the coastal provinces, he declared the independence of the five coastal provinces and put in place roadblocks to the capital to deal with this "unlawful sect". In an effort to strangle the economy of the central province even further, the president and his cronies started a campaign to blow up several crucial bridges and as such severed transport between provinces.

The overall effect of this dispute was an economic standstill of the country. ${ }^{3}$ As access to ports was controlled by the old regime and as no transport between provinces was possible, no fuel could get in the country (although a small black market in fuel developed). ${ }^{4}$ From February 2002 onwards, motorized

\footnotetext{
${ }^{2}$ The own polling results of the group around the opposition leader showed around $52 \%$ of the votes for Ravalomanana. The election monitoring committee arrived at a number just above $50 \%$. However, none of these two sources had data for all the voting bureaus.

${ }^{3}$ In July 2002, the government predicted for 2002 a negative growth of BNP of $-10.7 \%(-19.7 \%$ for the secondary sector, $-14.6 \%$ for the tertiary sector, $-1.2 \%$ for the primary sector) (Government of Madagascar 2002).

${ }^{4}$ This situation continued even after the situation was resolved as the foreign exchange market stopped functioning
} 
transport became rare in the whole country (in the central as well as the coastal provinces). ${ }^{5}$. Most firms that had to import or export goods closed down and the number of unemployed was estimated to rise to around 150,000 in total for the country, most of them in the capital (Government of Madagascar 2002). ${ }^{6}$

The situation was resolved at the end of June 2002 after the opposition leader secured the support of the army which gradually took over the coastal provinces. Most of the international community had recognized Ravalomanana as the new president by the end of June and life slowly returned to normal. In the beginning of August 2002, most fuel stations were up and running again. Although this crisis proved dramatic for the people of Madagascar, there are clearly lessons to be learned of the impact of such an exogenous shock on the functioning of the economy and the delivery of social services.

\section{Conceptual framework}

The level at which public services are actually provided depends on both supply and effective demand. ${ }^{7}$ Understanding public service provision therefore requires modeling both. There are many factors that influence supply and demand for public services. Many of them are time-invariant - or change slowly. In our empirical analysis, they are controlled for using fixed effects and can therefore be omitted from the discussion of the conceptual framework.

We first focus on user fees. Let $Q_{i t}$ be the quantity of public service actually consumed at time $t$ in facility $i$. How $Q_{i t}$ can be measured in practice depends on the time frame of the analysis and the

\footnotetext{
during the crisis and the petroleum companies were unable to pay for deliveries due to this situation. The foreign exchange market had been closed down as foreign assets of the Malagasy government had been frozen by the French and the American government after they had received conflicting letters of two different central bank directors (one for each government).

${ }^{5}$ Alistair Leithead of the BBC documented the black market fuel trade. He reported as follows (BBC, May 23, 2002): "About three miles off the coast a boat laden with fuel, which rumour says comes from South Africa, is illegally moored and ready to sell in bulk to anyone prepared to make the trip. Dhows, small traditional sailing boats, make the risky journey... In Mahajanga, the petrol pumps are empty, but the black-market traders sell for 2,500 Malagasy francs, about 35 cents, a litre. But there is not a huge amount of fuel available in the town. Most goes into barrels and heads down the road to Antananarivo. . By the time the barrels cross the [roadblocks] they are worth 9,000 Malagasy francs, $\$ 1.20$ at the black-market exchange rate. Some petrol is sold on the way, but it is too risky to enter the city after dark because of gangsters. They park up and wait for first light. In Antananarivo, fuel is sold for between 12 and 14,000 Malagasy francs a litre, $\$ 1.75$. The people you see in the street siphoning off the precious liquid into cars and vans pay even more. Ordinary consumers pay at least double. The political crisis has produced a whole new trade in fuel, becoming more entrenched as the deadlock continues."

${ }^{6}$ Lack of economic activity also led to lack of income for the government. It was estimated in May 2002 that the government only obtained $45 \%$ of the planned income for that period (Government of Madagascar 2002).

${ }^{7}$ In the case of public services, the distinction between need and effective demand is particularly acute: many people may need medical attention, for example, but fail to receive it because they cannot bear the cost. Effective demand normally increases with income. In contrast, the need for education or health care is typically highest among the poor. In this paper, we regard the level of provision as an approximate measure of the extent to which the need for public services is actually met.
} 
availability of data. The price $P_{i t}$ charged for the service - the user recovery fee - is determined by the political process and is regarded as exogenous by local providers and consumers. While this assumption need not be adequate for many parts of the world, it is a fair approximation of what took place in Madagascar over the short interval under study. With price fixed exogenously, the market for local provision clears through rationing of supply or demand (Benassy 1982).

The supply $S_{i t}$ of public service in facility $i$ depends on the availability of drugs and other materials $M_{i t}$. Availability is presumably influenced by the transport cost $C_{i t}$ between facility $i$ and the nearest supply center, which is typically the nearest large town. In the long run, local supply $S_{i t}$ also depends on the facility's financial situation and hence ultimately on $P_{i t}$. While the financial sustainability of the recovery fee waiver is in question (e.g. Programme Ilo 2003b, Programme Ilo 2003a), finance does not appear to have been a separate additional constraint during the period under investigation. Demand for the service depends on user fee $P_{i t}$ as well as on the income of potential consumers $Y_{i t}$. The more poor people there are in location $i$ at time $t$, the lower effective demand is expected to be, controlling for $P_{i t}$.

The data generation process can thus be represented as follows:

$$
\begin{aligned}
Q_{i t} & =\min \left\{S_{i t}, D_{i t}\right\} \\
S_{i t} & =S\left(M_{i t}, \eta_{i}, \theta_{t}\right) \\
D_{i t} & =D\left(P_{i t}, Y_{i t}, \lambda_{i}, \theta_{t}\right)
\end{aligned}
$$

where greek letters $\eta_{i}$ and $\lambda_{i}$ denote time-invariant factors affecting the model and $\theta_{t}$ denotes common time effects. $Q_{i t}=\min \left\{S_{i t}, D_{i t}\right\}$ because of rationing: if supply is binding and there is excess demand, $Q_{i t}=S_{i t}$; in contrast, if demand is binding and there is excess supply, then $Q_{i t}=D_{i t} .^{8}$

The above model forms the basis for our testing strategy. Our first model (Model 1) is a reduced equation of the form:

$$
Q_{i t}=f\left(P_{i t}, \theta_{t}, \mu_{i}\right)
$$

\footnotetext{
${ }^{8}$ There are many ways by which a rationed market may clear. For instance, beneficiaries may be discouraged from applying for services by long waiting times, short hours of operation, dismissive staff, and bad quality of service. For the purpose of the analysis presented here, how rationing occurs is inessential and is ignored here.
} 
where $\mu_{i}$ is a fixed effect specific to facility $i$. Equation (3.1) is estimated using data from before the crisis, during the crisis, and after the crisis. It evaluates the net effect of a change in user fee $P_{i t}$ on the provision of public service $Q_{i t}$. Coefficients for the time dummies evaluate the aggregate effect of the blockade and its aftermath on public service delivery.

Equation (3.1) does not, however, control for changes in supply and demand that may have taken place at the same time. We therefore estimate another, more complete model (Model 2) that includes supply and demand shifters $M_{i t}$ and $Y_{i t}$. We also include transport $\operatorname{costs} C_{i t}$ as proxy variable for other changes in demand and supply. The estimated model is of the form:

$$
Q_{i t}=f\left(P_{i t}, M_{i t}, Y_{i t}, C_{i t}, \theta_{t}, \mu_{i}\right)
$$

More complicated models are also conceivable. For instance, it is possible that demand depends on the quality of service consumers are likely to receive, that is, on $M_{i t}$. Alternatively, public service providers may request more $M_{i t}$ from the central government if local demand increases. This makes $M_{i t}$ endogenous. In the empirical analysis, we control for this possibility by instrumenting $M_{i t}$.

Before turning to the data, it is important to recognize that the approach described above can only identify the effect of a change in user fees on short-term provision. In the long run, whether or not providers collect user fees may have dramatic consequences on the financial viability of public services. In the long run, not charging user fees may have dramatic negative consequences on the poor if it erodes the quality and quantity of health and education services available to them. Subsidized service provision also generates excess demand and rationing, thereby making it possible for staff to extract side payments. All these important issues are ignored here.

\section{The data}

Three types of surveys - at the level of the commune, health center, and school - were organized at the end of 2002. The main purpose was to evaluate the effect of the political turmoil and of the policy changes on the functioning of the economy and on the delivery of social services. Most questions were therefore formulated as recall questions on the period before (November/December 2001), during (May/June 2002) 
and following the political crisis (November/December 2002).

Data collection was undertaken by the USAID-funded Ilo program, in collaboration with INSTAT and FOFIFA. ${ }^{9}$ This project has a long experience collecting data in Madagascar and had at the end of 2001 completed a socioeconomic census of all communes in the country. The commune census was used to set up a stratified sampling frame in a way to have the collected data be representative of the rural situation at the national and provincial level. Fivondronona (districts) were divided in six strata depending on the distance to the capital of the province (close, medium, far) and on the availability of a tarred road. In each strata, one fivondronana was selected for every province. In each fivondronana (36 out of 111 in total), four communes were selected randomly. Via interviews with key informants and focus groups - typically local administrators, public servants, traders and farmers - the survey collected detailed information on the socio-economic situation at the commune level. This communal survey was only held in rural communes given the difficulty to obtain reliable overall estimates on the heterogeneous population of large urban centers.

The results of the focus group interviews illustrate the dramatic impact of the political crisis (Tables 1 and 2). As the regular distribution channels of fuel were disrupted during the political crisis, prices of fuel skyrocketed (as it was only available on the black market). This led to a doubling of transport costs for personal travel as well for shipping of goods (Table 1). It led also to a dramatic reduction in the availability of means of transport. $80 \%$ of motorized transport was estimated to have been immobilized during the crisis (Government of Madagascar 2002). The transport situation improved after the political crisis was resolved but transportation costs at the time of post-crisis survey had not come down to the level of before the crisis.

During the crisis, prices of imported goods increased dramatically while goods not made locally became unavailable. Prices for basic consumption goods (salt, sugar, vegetable oil, kerosene) at least doubled. Producer prices decreased slightly during the crisis - and the number of traders that bought producer goods declined due to the problems with transport - while agricultural wages remained stagnant (Table 2). Consequently, the purchasing power of rural households declined and poverty increased significantly

\footnotetext{
${ }^{9}$ INSTAT is the statistical institute of the Ministry of Economy and Finance. FOFIFA is the agricultural research center within the Ministry of Scientific Research.
} 
due to the political crisis. Almost two thirds of commune focus groups stated that the effect of the political crisis was the worst welfare shock in the commune over the last ten years - in a country that is regularly hit by cyclones, droughts, plant diseases or locus invasions. To have some quantitative idea on the effect of the political crisis on monetary income, communal focus groups were asked to evaluate its evolution for an average household in the commune. According to focus group estimates, the income of an average household decreased by almost $50 \%$ during the crisis and at the end of the year was $20 \%$ lower compared to the same period the previous year (Table 2).

Focus groups were asked to evaluate the percentage of the population that had difficulties or was unable to pay for costs related to health care and schooling. While admittedly a crude method, this number turned out during pre-testing to be quite easy to estimate. In our analysis, we use this number as an indication of poverty and demand changes in the commune. Survey results indicates that the poor rose by $6 \%$ on average ( $13 \%$ for the median) during the crisis (Table 1$)$. This is a dramatic increase given that we are comparing the harvest period (May/June) to the lean period (November/December). Using the same period in the year, the post-crisis poverty level shows an average increase of $2 \%$ (5\% for the median) compared to the previous year. ${ }^{10}$ As the transportation blockade was resolved in July, it seems that people were able to get back to business as usual and by the end of the year had made up for some lost earnings.

A key objective of the survey was to study the impact the political crisis and the ensuing reduction in user fees on social services. To this effect, health centers and schools were visited and surveyed separately. There is a health center in every commune in Madagascar. This health center was visited in every sampled commune. On average, 24 health centers were surveyed per province. The number of visits per month in the health center is used as a proxy for the quantity of public services actually consumed $Q_{i t}$.

In each commune, there are a large number of public primary schools. Two of them were sampled: one in the center of the commune and one 'remote' school that was at least 3 kilometers away from the center. Some 284 schools were visited in total. For schools, the total number of students in the primary school is used as dependent variable $Q_{i t}$ in our analysis.

\footnotetext{
${ }^{10}$ Other data sources confirm the magnitude of these numbers. Using a detailed expenditure survey that was done at the end of 2001 and at the end of 2002, INSTAT (2003) estimates rural poverty to have increased by $9 \%$.
} 
Table 1 illustrates the significant increase of the number of books given to the schools after the crisis. This is mostly due to the activities of a World Bank financed program (CRESED) that markedly increased its disbursement in the aftermath of the crisis. In the regression analysis, we use the number of books as our measure of quality $M_{i t}$ for education. In the case of health care, we use the availability of a working fridge as proxy variable for $M_{i t} \cdot{ }^{11}$ To control for potential endogeneity of $M_{i t}$, we use the number of media outlets, the price of rice, and the proportion of ethnic highlanders in the commune population as instrumenting variables. We have no reason to suspect that changes in these variables over time would affect public service delivery directly. Descriptive statistics for these variables are presented in Table 1.

\section{Public service provision during the study period}

Before turning to the econometric analysis per se, we examine the descriptive evidence in detail. The functioning of the health and education sectors was seriously affected during the study period due to demand and supply changes. We first discuss supply and demand shocks in the health sector. Next we examine supply and demand shifts in education during the study period.

\subsection{The health sector}

Manpower in this sector was surprisingly resilient during the crisis: there is anecdotal evidence that some health staff were not able to report for work, but this was not an overall trend (Table 2). ${ }^{12}$ Some health centers adjusted to the crisis through a reduction in opening hours, especially in urban centers. This was generally implemented to allow staff more time to walk home given the lack of motorized transport. When the transport crisis was over, opening hours were adjusted back to the pre-crisis schedule.

Another indication of supply changes is the evolution of the availability of different medicines. We measure drug availability by taking a simple average of the most frequently used medicines. According this measure, availability of medicines declined from $89 \%$ to $73 \%$ between December/January 2002 and

\footnotetext{
${ }^{11}$ Other available measures of health or schooling quality either did not change much over the duration of our short panel, or were too endogenous to be useful. The availability of drugs is a good illustration: survey results show that availability of drugs fell after the end of the crisis. This is undoubtedly a result of a sharp increase in visits by patients. Given the small size of our sample and the difficulty of finding suitable instruments, it is best to focus on one key quality indicator.

${ }^{12}$ For Madagascar as a whole, the Ministry of Health estimates that during the crisis around 250 doctors left the health center to which they were assigned. At the time of the survey, 181 had returned to their post.
} 
May/June 2002 and got even slightly worse after the crisis (Table 2). The worsening situation after the crisis has been blamed on an increase in the number of visits resulting from the change in pricing policy of the new government, and on the bad organization of the distribution of the free medicines. ${ }^{13}$

Access to electricity in rural areas did not show any major change during the crisis (Table 2). ${ }^{14}$ Some $50 \%$ of the public rural health centers did not have electricity before the crisis and this proportion only increased marginally during the crisis. More worrisome was the situation with fridges, used to store medicines and vaccines. While $73 \%$ of the health centers had a working fridge before the crisis started, this number dropped to $56 \%$ in June (Table 1). The reason for the decline was lack of gas and fuel, the major sources of power for fridges in rural areas.

Given the dramatic circumstances, the supply side of the health sector appears to have been surprisingly little affected by the transportation shock. The obvious explanation is that only motorized transport was touched by the crisis. The supply side of the health sector was thus only affected for these goods and services that depend on motorized transport. However, while the supply side was less affected than expected, this does not mean that the use of health services stayed constant. As shown in Table 1, the median number of visits to health centers dropped. The staff at the health center were asked to voice their opinion on the reason for change. Their responses are summarized in Table 3. The major perceived reason for the drop in the number of visits to health centers during the crisis was the increase in poverty. In $54 \%$ of the health centers that noticed a drop in the number of visits, the staff of the center related this to the increase of poverty and the inability of people to pay the fees (Table 3$).{ }^{15}$ Only in $17 \%$ of the cases did they explain the drop in visits by a lack of staff or medicines.

This state of affairs was one of the reasons the new government intervened after the crisis. To reduce the welfare impact of increased poverty, the pricing policy of public services was changed. The new president declared in August that user fees would (temporarily) be abolished in public health centers.

\footnotetext{
${ }^{13}$ After the crisis, SALAMA, the governmental medicine distribution center, bought 20 billion Fmg (3 billion $\$$ ) worth of medecines for free distribution. Since these medecines were only distributed by the end of December, they are not captured in our survey.

${ }^{14}$ The new government was able to bring in occasional supplies of fuel in well protected convoys. This fuel was used as part of a strategic stock to keep electricity going and for other essential activities.

${ }^{15}$ It was stated that in case of illness, patients who no longer came to health centers either did not seek formal services at all or did visit traditional healers. The people in charge of the health estimated that, if there was a drop in the number of visits in their center during the crisis, a significant part of their normal patients did not receive any treatment at all anymore. A quarter of the centers said that patients would go to traditional healers. This is especially the case for rural areas. It is only in urban centers that patients seemed to have had at least partial substitution possibilities.
} 
This policy, however, was unevenly applied in space and time. Table 1 shows that simple medicines and consultations were offered for free in $15 \%$ of the public rural health centers before the crisis. By the time the survey team visited them in November 2002, only $74 \%$ of surveyed health centers were refraining from charging user fees. The reason for this was the new government took time to assert its authority in all provinces. The new policy was well applied in the central province of Antananarivo where $93 \%$ of the public centers had abolished fees by the time of the survey. In that part of the country, the median month for abolishment was August. This compares to the northern province of Antsiranana where only $55 \%$ had abolished cost recovery policies by November.

Table 1 shows the mean and the median of the number of visits to health centers in the period December 2002, May/June 2002 and December 2003. Compared to the situation prior to the crisis, the number of visits to public rural health centers decreased slightly during the crisis period and increased significantly afterwards. ${ }^{16}$ Monthly visits post-crisis almost doubled compared to the previous year. Answers to qualitative questions asked to health staff indicate that the main perceived reason for the increase in the number of visits is the elimination of user fees (Table 3).

Studies in other settings have shown that poorer non-educated households are hurt more by macroeconomic shocks (e.g. Glewwe \& Hall 1998, Frankenberg, Smith \& Thomas 2003). Pro-poor policies have not been followed in health service delivery in Madagascar (e.g. Glick \& Razakamamantsoa 2001, Glick, Razafindravonona \& Randretsa 2000, Castro-Leal, Dayton, Demery \& Mehra 1999). The poorer part of the population is thus more likely to shift away from formal health services in response to a large negative macro-economic shock simple because they can no longer afford it. This seems to have been the effect of the political crisis in Madagascar, based on the perceptions of the persons in charge of the health center. The mean and median of the drop in visits of the poorer part of the population indicates that their perceived number of visits is down by $35 \%$. This compares to a perceived doubling of the visits of the poor post-crisis, which is generally attributed to the abolishment of user fees. In Section 5, we use multivariate statistical analysis to disentangle income and price effects.

\footnotetext{
${ }^{16}$ One health center in one of the communes closed down completely. Given that no data were available on this health center, it was not taken into account for further analysis.
} 


\subsection{The education sector}

The impact of the political crisis was also - but less - visible in the education sector (Lassabille \& Tan 2003). As in the health sector, working hours were reduced. Some $56 \%$ of schools experience interruptions in teaching, mostly due to strikes and rallies in favor of the two presidential candidates. In urban areas, all schools were affected and, on average, cancelled classes for 58 days (Programme Ilo $2002 a$ ). After the end of the strikes, the teaching schedule was re-organized (as in health centers) to better face the transportation problems caused by fuel shortages. In general, this change led to a reduction in the total number of hours of class per day. Due to these changes, the required annual number of hours of classes was not reached during the academic year 2001/2002. ${ }^{17}$

Mostly due to reasons linked with the political crisis, the passing rate at the CEPE, a standardized national examination at the end of the primary school, showed a significant $13 \%$ decline (Table 2 ). ${ }^{18}$ The rate of child absenteeism increased by $20 \%$ in May 2002 compared to the first trimester of the school year. This increased has been blamed by survey respondents on child labor as well as on the difficulties encountered by parents in paying for the school expenses (school fees, food, and transportation). Similar effects of a decrease of income on education have been documented in other low income countries (e.g. Basu 1999, Jacoby \& Skoufias 1997, Ablett \& Slengesol 1999, Thomas, Beegle, Frankenberg, Sikoki, Strauss \& Teruel 2001, Davies 1996). However, child absenteeism should not entirely be attributed to the crisis. Demand for child labor always increases in April-May in rural areas because it corresponds to the harvest period of rice, the major staple in Madagascar. Only to the extent that households' income decreased due to the crisis and that the rural families had to rely more on family labor instead of wage labor can we say that the crisis contributed to an increase of the child labor that led to more absenteeism than in a normal year.

The overall presence of the teachers was seemingly little affected by the crisis (Table 2). The number of teachers that abandoned their post did not change significantly compared to a normal year. Salaries

\footnotetext{
${ }^{17}$ The political crisis created disturbances in the school year calendar. If the school year normally ends in late June, the official examinations that mark the end of the school year were delayed for about 1 month. Moreover, the school year 2002-2003 started only in the first week of October, although it was initially expected to start in mid-September.

${ }^{18}$ The high decrease for the passing rate in the province of Antsiranana (49\% in 2000/2001 compared to 14\% in $2001 / 2002$ ) is partly explained by confusion on the CEPE exam. In most of the province two exams were administered (referred to as the Ratsiraka exam and the Ravelomanana exam). Only a small minority of students showed up for the second exam which was held one month into their normal vacation period.
} 
were mostly paid during the crisis as only around $10 \%$ of the schools reported a delay or a stop in the payment of salaries. ${ }^{19}$ The transportation problem seem to have caused two types of delays: it took teachers longer to get to the capital of the Fivondronana, where they receive their salary, and sometimes the arrival of their salaries was delayed in the capital of the Fivondronana. However, while few teachers abandoned teaching altogether, an increase in teachers absenteeism was noticed compared to the period before the crisis.

In response to the expected negative impact of the political crisis, the new president changed user fee policies in the education sector as well and announced that the government would waive the tuition fee for the school year 2002/2003. Each student inscription would lead to an extra allocation of 10,000 Fmg (15,000 Fmg for the capital) towards the school. ${ }^{20}$ However, the distribution of these funds was not without difficulties. Most the public schools had not received these funds at the beginning of the school year. At the moment of the survey in November, only $41 \%$ of the public primary schools had received all or part of the promised funds. Therefore, a significant number of schools asked parents to pay a tuition fee. The schools that asked for a tuition did so mostly to deal with liquidity problem caused by the late arrival of the funds. ${ }^{21}$

Primary school enrollment rates in the school year 2002/2003 increased dramatically. They increased by $15 \%$ compared to the previous school year for the public primary school as a whole (Table 1 ). The number of first grade students increased even by $20 \%$ (Table 2). Even in higher years, the increase in the number of students is significantly above population growth. To have more insights in the perceived reason for the change in the number of students, school staff of the school were asked why they thought the change occurred. The major reason mentioned for the increase is the decrease in schooling costs. This is not the only reason, however: other reasons make up $30 \%$ of the explanations (Table 3$){ }^{22}$ Enrollment

\footnotetext{
${ }^{19}$ In the communes situated far from the capital in each province, the delay in the payment of the salaries has had an impact on absence of teachers: while the average number of days of absence per month is estimated at 1 or 2 days, the teachers were reported during the crisis to be absent for 5 to 10 days per month.

${ }^{20}$ One part of this amount, theoretically not higher than $7500 \mathrm{Fmg}$, would be used towards the payment of the general costs and inscription costs. The rest would be used towards the school budget ("Caisse Ecole").

21 of the economy and the lack of income seem to have led to a liquidity problem for most households during the crisis and therefore, monthly school fees for the private schools could not be paid in some cases: 19 per cent of the students in the private schools are reported - an estimate by the school staff - to not be able to regularly or entirely pay their fees. However, private schools offered adjustments. While school fees did not change significantly during the crisis compared to the period before, almost all schools allowed parents to pay school fees later than normal.

${ }^{22}$ One explanation was extra efforts to explain the utility of schooling to the local population. Another important reason (esp. in the central and eastern regions) that was mentioned was the availability of a birth certificate. While children did
} 
rates could have risen even more as $20 \%$ of the schools reported that they had to refuse students due to the lack of space (Table 2).

\section{Econometric analysis}

The descriptive and qualitative evidence presented in the previous section suggests that the large changes that affected the provision of health and education services in Madagascar were driven at least in part by an increase in poverty during the crisis and the removal of user fees after the crisis. However, we also found evidence of supply shifts, particularly in the availability of school books, drugs and working fridges. To disentangle the respective effects of these various factors, we need to rely on the multivariate approach outlined in Section 3. To this we now turn.

Our strategy is to use variation across the sample in changes across period to isolate the respective effects of supply and demand shifts. Fortunately, we have a lot of variation across the sample, which makes identification possible in spite of the small size of the sample. For instance, the drop in the number of patient visits during the crisis is not identical across health centers: one center reports a drop to $9 \%$ of its pre-crisis level while another reports almost a fourfold increase. Similar cross-section variation is noticed in the period after the crisis.

We begin by estimating a reduced-form model (Model 1). Estimated coefficients are presented in Table 4. The first column measures the effect on health care. Our dependent variable is the number of visits by patients to each health center covered by the survey. The second column measures the effect on education. Student enrollment is our measure of the quantity of education services consumed by the population. Both dependent variables are in logs, as well as school fees. ${ }^{23}$ Coefficients thus have the usual elasticity interpretation. Both regressions are estimated using fixed effects specific to each facility.

Coefficients of the time dummies suggest that the blockade (period 2) and subsequent recovery (period 3) had large effects on the provision of public services across the sample. The effect is particularly noticeable in health care, where the number of visits dropped by $17 \%$ in June 2002 relative to December

have to possess a birth certificate before to be accepted in public schools, this condition was annulated in a significant number of communes post-crisis. Alternatively, communes made sure that enough copies were available this year to ensure that more children could go to school.

${ }^{23}$ To avoid losing zero observations after taking logs, we take the log of school fees plus 1 FMG. 
2001. Perhaps even more remarkable is the expansion of service in November 2002, with an average increase of $39 \%$ for health care and 8\% for school enrollment relative to December 2001.

The effect of user fees is also clearly apparent in the results, as both coefficients are significant. A $16 \%$ increase in the number of visits to health centers is associated with the elimination of user fees. To interpret the school fee coefficient, note that the average log of school fees is 6.5. A coefficient of 0.01 thus means that an elimination of school fees is associated with a $6.5 \%$ increase in school enrollment. The order of magnitude of this elasticity may appear small but one should keep in mind that it only measures a short-term response to a temporary measure. The policy measure is temporary, so parents who enroll an additional child in school expect to pay the school fee in the future. If the abolishment of school fee were made permanent, we would expect a larger response. Moreover, as far as the effect of school fees on school entry is concerned, children who enter school for the first time are normally enrolled in school around a given age. Consequently, only children who are within that age range may be affected by the measure; older kids who never went to school or dropped out at a young age are unlikely to reenter school in response to a change in fee. For these reasons, we would expect the long-term response to a change in user fee to be stronger (Glick \& Sahn 2001).

As discussed in the conceptual section, Model 1 does not adequately control for demand and supply shifters. We therefore reestimate the model with additional controls. Results are summarized in Table 5. The first and third column report straight fixed effect estimates; the third and fourth column report estimates in which the availability of a working fridge and the number of books distributed to schools are instrumented. We first discuss uninstrumented results.

We begin by noting that the results from Table 4 are confirmed and, in general, magnified by the inclusion of additional demand and supply shifters. The blockade is associated with a $26 \%$ drop in visits to health centers and a $3 \%$ drop in school enrollment. In contrast, the expansion of service in late 2002 represents a $26 \%$ increase in health center visits relative to December 2001, and a $7 \%$ increase in school enrollment. User fees remain significant and their coefficient is larger: a removal of user fee is now associated with a $21 \%$ increase in health center visits and a $9 \%$ increase in school enrollment $(0.014 \times 6.5)$.

Supply shifters have the expected sign: the availability of a working fridge (used to store vaccines and 
medicines) tends to raise health center visits while the free distribution of books to a school raises school enrollment. The latter effect, however, is not significant. Demand also has the anticipated effect. Our demand shifter is the proportion of poor in the commune where the facility is located. Poverty figures were collected in each of the three survey visits. Results show a strong effect of poverty on health care: the average 13\% increase in poverty between December 2001 and June 2002 is associated with a 3.7\% drop in health center visits. The effect is strongly significant. In contrast, the effect on school enrollment of short-term changes in poverty is not significant. This finding contradicts research findings by Jacoby \& Skoufias (1997) and by Sawada (2002) in South Asia. These authors show that temporary shocks induce households to withdraw children from school. A similar effect is not observed here, possibly because the blockade affected families late in the academic year when enrollment decisions had already been made, and was resolved before new enrollment decisions were made for the following academic year.

Contrary to expectations, we find that changes in transport costs did not have a direct effect on public service provision once we control for time dummies and demand and supply shifters. Transport costs, however, are found to have a negative effect on these shifters: locations in which the cost of transport to the nearest major town increased more during the blockade endured a larger increase in poverty and a larger reduction in supply factors.

Columns 2 and 4 of Table 5 present regression results in which we instrument supply shifters. The reason for doing so was explained in Section 3: changes in demand may incite facilities to secure more inputs $M_{i t}$ from the central government. To control for this possibility, we instrument the availability of a fridge and the number of books distributed to the school. Instrumenting regressions are presented in Table 6. Our instruments are the number of media outlets in the commune, the number of media outlets interacted with period 3 , the price of rice in the commune, and the share of ethnic highland people in the commune crossed with period 3. The number of media outlets is a proxy for communication devices between the commune and the central government; presumably, communes that have more media outlets are better informed about what goes on in the capital city, and thus better able to communicate their requests and grievances to central government. We also interact this variable with the period 3 dummy to reflect the change in government that took place in the Summer and the widespread changes in public 
service delivery that ensued. The price of rice is used as proxy for the price level in the commune: places where prices increased more during - decreased less after - the blockade may lobby for more government support in the form of supplies. ${ }^{24}$ Finally, ethnicity may affect the responsiveness of central government to local demands. Inhabitants of Madagascar descend from two main settlement waves: Malays who settled predominantly in the highlands (many centuries ago) and Africans who settled primarily on the West coast. Although the two populations are now largely mixed, descendants from highland settlers have traditionally dominated island politics. As a result, we expect them better able to benefit from the large political changes occurring in period $3 .^{25}$ Instruments are jointly significant, as confirmed by the F-test reported at the bottom of Table 6 . Overidentification test results also confirm that instruments can safely be regarded as exogenous in the service provision regressions.

Instrumenting regressions by and large confirm our expectations. Communes where the price of rice grew more than elsewhere are also those where fridges were more available. Communes with more ethnic highlanders and more media outlets (nearly significant) received more school books from the central government. We also find that transport costs have a large negative impact on the availability of a working fridge.

Turning back to Table 5, we find that instrumented results by and large resemble uninstrumented ones. It is therefore not surprising that, in both cases, a Davidson-MacKinnon test fails to find evidence of endogeneity. Instrumented regression results are nevertheless less precise, with several coefficients no longer significant. Since endogeneity turned out not to be a concern after all, instrumented results should not be given too much weight.

\section{Conclusions}

This study looks at public service delivery in the face of a policy shock and change in user fee. The effect of those on public service delivery has been a hotly debated issue ever since structural adjustment programs have been put in place and especially since the Asian crisis (e.g. Cornia, Jolly \& Stewart 1987, Sahn \&

\footnotetext{
${ }^{24}$ The validity of this instrument hinges on the fact that poverty is measured not by nominal income but as a percentage of the population that is poor. Consequently, much of the possible effect of a change in rice price on demand for services is capture by our poverty variable.

${ }^{25}$ The use of all four instruments in both instrumenting regressions is for convenience and symmetry only. Virtually identical results are obtained if we drop non-significant instruments.
} 
Bernier 1995, Sahn, Dorosh \& Younger 1997, Stewart \& Ranis 1999). However, good microdata that measure the impact of macroeconomic shocks and changes in user fees have been lacking.

Madagascar provided the stage for a natural experiment to ascertain the effect of such changes. A dispute regarding the outcome of the presidential election held in December 2001 led to a 6 month-long blockade of the central highlands. When this blockade was finally lifted, the new president temporarily suspended user fees in schools and health centers. This measure, however, was not applied immediately in all rural communes, due to political uncertainty and imperfect communication with the capital. This sequence of events provides a natural experiment to study the effect of a macro-economic shock and a reduction in user fees on public service provision.

Geographical isolation also plays a role in social service delivery. It has long been noted that public services provision in poor countries is better in urban than rural areas. But it is not entirely clear why this is the case. Supply may be lower in rural area - because of high delivery costs due to low population density, transport costs to rural areas, capacity to attract qualified staff, etc. Demand may also be lower because rural incomes are lower. This paper provides evidence indicating that, contrary to expectations, variations in transport costs over time do not have a major impact on service provision. Poverty, in contrast, has a large significant negative effect on health care.

We find that the education sector showed the least effects of the shock. Some schools had to close during two months of strike and then had to deal with transportation difficulties triggered by the rapid increase in fuel prices. The sector nevertheless adjusted to face these problems. The teaching schedule and the timing of the 2001/2002 and 2002/2003 school years were adjusted and payment facilities for school fees were put in place to allow students to finish their school year. These findings came as a pleasant surprise to most observers who expected more dramatic consequences. ${ }^{26}$

The dramatic effects that were predicted in the health sector (Harris 2002) did not realize either. As the health sector depends more on outside deliveries than the education sector, this sector was more affected by the transportation shock induced by the political crisis. However, all the activities that involved only local transport continued. Again, the government adjusted in the face of the shock. In this

\footnotetext{
${ }^{26}$ Cameron (2002) shows similar effects in a study on the effect of the Indonesian crisis on children: school attendance dropped slightly after the onset of the crisis but rebounded afterwards to higher than pre-crisis levels.
} 
case, the government used its strategic fuel stock, to the extent possible, to keep electricity and fridges running. Some hospitals reduced consultation fees to allow patients to continue to use their services and donors intervened to bring in medicines. Hence, the major cause of the decline in visits to hospitals was not lack of supplies but the lack of liquidity for households to pay for health care.

This study has shown a high resilience of service delivery. The results, based on qualitative and quantitative evidence, indicate that the decline in the use of services was in most cases not a supply problem as a significant number of hospitals and schools continued to deliver services. Most of the drop is explained by the lack of income and an increase in poverty which led to a decrease in access to liquidity and an increase in opportunity costs of the time of children. The role of demand is further emphasized by the significant increase in visits to health centers and school enrollment that followed the elimination of user fees. These results suggest that, in order to mitigate the effects of macro-economic shocks on access to public services, more attention should therefore be paid to the demand side, while keeping in mind that the long-run financial viability of public service delivery is essential to ensure continued provision.

\section{References}

Ablett, J. \& I. Slengesol. 1999. Education in Crisis: The Impact and Lessons of the East-Asian Financial Shock 1997-1999. Paris: Unesco.

Alderman, Harold, Peter F. Orazem \& Elizabeth M. Paterno. 2001. "School Quality, School Cost, and the Public/Private School Choices of Low-Income Households in Pakistan.” Journal of Human Resources $36(2): 304-26$.

Basu, Kaushik. 1999. "Child Labor: Cause, Consequence, and Cure." Journal of Economic Literature 37(3):1083-119.

Behrman, Jere R. \& James C. Knowles. 1999. "Household Income and Child Schooling in Vietnam." World Bank Economic Review 13(2):211-56.

Benassy, Jean-Pascal. 1982. "The Economics of Market Disequilibrium.". 
Cameron, L.A. 2002. The Impact of the Indonesian Financial Crisis on Children: Data from 100 Villages Survey. Technical report World Bank Washington DC: . Working Paper.

Castro-Leal, F., J. Dayton, L. Demery \& K. Mehra. 1999. "Public Social Spending in Africa: Do the Poor benefit?" World Bank Research Observer 14(1):49-72.

Cornia, G.A., R. Jolly \& Frances Stewart. 1987. Adjustment with a Human Face Volume 1. Protecting the Vulnerable and Promoting Growth. Oxford: Oxford University Press, Clarendon Press.

Davies, S. 1996. Adaptable Livelihoods. London: MacMillan.

Deininger, Klaus. 2003. "Does Cost of Schooling Affect Enrollment by the Poor? Universal Primary Education in Uganda." Economics of Education Review 22(3):291-305.

Fafchamps, Marcel \& Bart Minten. 2002. "Crime and Poverty: Evidence from a Natural Experiment." (mimeograph).

Frankenberg, Elizabeth, James P. Smith \& Duncan Thomas. 2003. "Economic Shocks, Wealth, and Welfare." Journal of Human Resources 38(2):230-321.

Gertler, Paul \& Paul Glewwe. 1990. "The Willingness to Pay for Education in Developing Countries: Evidence from Rural Peru." Journal of Public Economics 42(3):251-75.

Glewwe, Paul \& G. Hall. 1998. "Are Some Groups More Vulnerable to Macroeconomic Shocks than Others? Hypothesis Tests Based on Panel Data from Peru." Journal of Development Economics 56(1):181-206.

Glick, P. \& D. Sahn. 2001. The demand for Primary Schooling in Rural Madagascar: Price, Quality and the Choice between Public and Private Providers. Technical report Cornell Food and Nutrition Policy Program, Working Paper.

Glick, P., J. Razafindravonona \& I. Randretsa. 2000. Services d'éducation et de santé à Madagascar : l'utilisation et les déterminants de la demande. Antananarivo: INSTAT.

Glick, P. \& M. Razakamamantsoa. 2001. La distribution des services sociaux à Madagascar: 1993-1999. Antananarivo: INSTAT. 
Government of Madagascar. 2002. "Situation de Madagascar au 1er juillet 2002.". Paper presented at the conference of Amis de Madagascar.

Harris, N. 2002. Silent Mortality in Madagascar: Rapid Diagnosis and Contingency Plan. Antananarivo: USAID/JSI.

Jacoby, Hanan G. \& Emmanuel Skoufias. 1997. "Risk, Financial Markets, and Human Capital in a Developing Country." Review of Economic Studies 64(3):311-345.

Lassabille, G. \& J.P. Tan. 2003. "Student Public Learning in Primary Schools in Madagascar." Economic Development and Cultural Change 51:699-717.

Pradhan, Menno \& Nicholas Prescott. 2002. "Social Risk Management Options for Medical Care in Indonesia." Health Economics 11(5):431-46.

Programme Ilo. 2002a. Etude de l'impact de la crise politique sur le secteur de l'éducation de base. In Crise Politique Policy Brief. Vol. 6 Antananarivo, Madagascar: Programme Ilo and Cornell University.

Programme Ilo. 2002b. Impact de la crise politique sur le secteur santé: résultats de l'enquête rural et urbaine au niveau des centres de santé pendant le mois de juin 2002. In Crise Politique Policy Brief. Vol. 5 Antananarivo, Madagascar: Programme Ilo and Cornell University.

Programme Ilo. 2003a. Monitoring and analysis of the health sector post-crisis: the impact of the abolishment of the cost recovery policy. In Postcrisis Policy Brief. Vol. 2 Antananarivo, Madagascar: Programme Ilo and Cornell University.

Programme Ilo. 2003b. Monitoring of the education sector post-crisis: impact of the abolishment of the public school tuition policy. In Postcrisis Policy Brief. Vol. 5 Antananarivo, Madagascar: Programme Ilo and Cornell University.

Sahn, David E., Paul Dorosh \& Steven D. Younger. 1997. Structural Adjustment Reconsidered: Economic Policy and Poverty in Africa. Cambridge University Press. 
Sahn, David E. \& R. Bernier. 1995. "Have Structural Adjustments Led to Health Sector Reform in Africa?" Health Policy 32:193-214.

Sawada, Yasuyuki. 2002. "Income Risks, Gender, and Human Capital Investment in a Developing Country." (mimeograph).

Stewart, Frances \& Gustav Ranis. 1999. The Asian Crisis: Social Consequences and Policies. In Structural Aspects of the Asian Crisis. Paris: OECD pp. 133-62.

Thomas, Duncan, K. Beegle, Elizabeth Frankenberg, B. Sikoki, John Strauss \& G. Teruel. 2001. "Education in a Crisis." (mimeograph). 
Table 1: Descriptive statistics of variables used in regression analysis

\begin{tabular}{|c|c|c|c|c|c|c|c|c|c|c|}
\hline \multirow[b]{2}{*}{ Variable } & \multirow[b]{2}{*}{ Unit } & \multicolumn{3}{|c|}{$\begin{array}{c}\text { Pre-crisis } \\
\text { Nov./Dec. } 2001\end{array}$} & \multicolumn{3}{|c|}{$\begin{array}{c}\text { Crisis } \\
\text { May/June } 2002\end{array}$} & \multicolumn{3}{|c|}{$\begin{array}{c}\text { Post-crisis } \\
\text { Nov./Dec. } 2002\end{array}$} \\
\hline & & median & mean & std. dev. & median & mean & std. dev. & median & mean & std. dev. \\
\hline \multicolumn{11}{|l|}{ 1. Public health center } \\
\hline Number of visits per month & Number per health ctr & 62.50 & 117.44 & 320.72 & 50.00 & 117.35 & 478.49 & 104.62 & 208.23 & 622.82 \\
\hline Availability of working fridge & Yes $=1$ & 1.00 & 0.73 & & 1.00 & 0.56 & & 1.00 & 0.70 & \\
\hline Fee & Yes $=1$ & 1.00 & 0.85 & & 1.00 & 0.84 & & 0.00 & 0.26 & \\
\hline No of observations & & 138 & & & 138 & & & 138 & & \\
\hline \multicolumn{11}{|l|}{ 2. Public school } \\
\hline Number of students & Number per school & 181.00 & 243.82 & 195.90 & 168.00 & 229.68 & 183.69 & 209.00 & 280.37 & 226.83 \\
\hline Number of books & Number per school & 0.00 & 35.48 & 102.95 & 0.00 & 35.48 & 102.95 & 81.50 & 136.95 & 172.63 \\
\hline Fee & Malagasy franc & 3000.00 & 4172.46 & 3316.72 & 3000.00 & 4172.46 & 3316.72 & 0.00 & 1741.73 & 3603.94 \\
\hline No of observations & & 282 & & & 282 & & & 284 & & \\
\hline \multicolumn{11}{|l|}{ 3. Commune } \\
\hline Transport costs to major city & Malagasy franc & 25000.00 & 37037.88 & 33553.33 & 62750.00 & 73965.38 & 61002.42 & 35000.00 & 46793.23 & 42852.38 \\
\hline Media outlets (radio, TV) & Number & 1.09 & 1.09 & 0.88 & 1.09 & 1.12 & 0.90 & 1.09 & 1.11 & 0.90 \\
\hline Price of rice & Fmg/kapoaka & 700.00 & 726.42 & 281.89 & 650.00 & 689.97 & 356.45 & 750.00 & 784.18 & 332.18 \\
\hline No of temporary and chronic poor & $\%$ of pop. in commune & 55.00 & 53.75 & 24.72 & 68.00 & 60.49 & 26.72 & 60.00 & 55.65 & 25.07 \\
\hline Ethnic group of highlands & $\%$ of pop. in commune & 6.00 & 32.47 & 41.78 & 6.00 & 32.47 & 41.78 & 6.00 & 32.47 & 41.78 \\
\hline No of observations & & 138 & & & 138 & & & 138 & & \\
\hline
\end{tabular}




Pre-crisis Crisis Post-crisis

Unit Nov./Dec. 2001 May/June 2002 Nov./Dec. 2002

\section{Public health center}

Average number of staff per center

Availability of medicines

Availability of electricity

Perceived average change in the number of visits by poor patients compared to last year same time\#\#

\section{Public schoo}

Number of teachers per school

Number of students grade 1

Number of students grade 2

Number of students grade 3

Number of students grade 4

Number of students grade 5

Schools that refused students due to lack of space

Passing rate at CEPE* previous school year

If decrease, reason

Insufficient number of courses due to crisis

Lack of concentration due to crisis

Other reason linked to crisis

Reason independent of crisis

Total

\section{Commune}

Price of paddy

Price of salt

Price of sugar

Price of kerosene

Price vegetable oil

Agricultural wage level (male)

Perceived evolution monetary income avg hh compared to last year same time

During the last ten years, political crisis
4.09

0.86

50.35

$\%$

$\%$

Number

Number

Number

Number

Number

Number

$\%$

$\%$

$\%$

$\%$

$\%$

$\%$

\begin{tabular}{crrr} 
Fmg/kg & 1825 & 1650 & 1977 \\
Fmg/kg & 369 & 1168 & 566 \\
Fmg/kg & 5392 & 12034 & 6357 \\
Fmg/kg & 3671 & 14434 & 5047 \\
Fmg/l & 7727 & 15654 & 10677 \\
Fmg/day & 8407 & 8675 & 8893 \\
& & & \\
$\%$ & & $-46 \% * *$ & $-20 \%$ \\
$1=y e s ; \%$ & & $64 \%$ \\
\hline
\end{tabular}

4.05

0.73

4.09

48.94

50.35

$-27 \% * *$

$+55 \%$

5.01

$76.16 \quad 96.55$

$50.71 \quad 59.81$

$46.77 \quad 54.63$

$31.57 \quad 39.11$

$24.47 \quad 30.28$

20.77

46.86

18.60

44.19

17.05

20.16

100.00

1977

5047

677

$20 \%$

\#: simple average of the availability $(1=$ yes; $0=$ no $)$ of oral contraceptives, condoms, aspirin, paracetamol, amoxyciline,cotrimoxazole, peniciline, doxycycline, tetracycline, anti-malaria, vaccines BCG, polio, DTCoq, rougeole, oral hydratation

\#\#: perception of the staff of the health center

*: national standarized test at the end of primary school

**: only based on half of the sample visited in April/May 2002 
Table 3: Perceived reasons for change in public service use (compared to the same period last year)

\begin{tabular}{lrr}
\hline & \multicolumn{2}{c}{ Rural centers/schools } \\
& Number & Percentage \\
\hline 1. Public health center & & \\
If decrease of visits, major reason for decrease during the crisis* & & 2 \\
Transport costs have increased & 2 & 22 \\
Lack of staff or medicines & 17 & 51 \\
People are not able anymore to pay fees & 38 & 24 \\
Other & 18 & 100 \\
Total & 75 & \\
Lack of staff & & 19 \\
Lack of medicines & 4 & 43 \\
Patients can't pay tariffs & 9 & 14 \\
Other & 3 & 24 \\
Total & 5 & 100 \\
If decrase of visits, major reason for decrease after crisis & 21 & 4 \\
Better quality of service & & 6 \\
Patients don't go to other centers anymore & 4 & 45 \\
Reduction cost of medicines & 7 & 31 \\
Abolishment of consulting fees & 49 & 14 \\
Other & 33 & 100 \\
Total & 15 & 108 \\
\hline
\end{tabular}

\section{Public school}

Major reason for absenteism during crisis*

$\begin{array}{lrr}\text { Lack of teachers } & 2 & 2 \\ \text { Parents could not pay the school fees } & 0 & 0 \\ \text { Parents could not buy school supplies } & 2 & 2 \\ \text { Food problems } & 42 & 50 \\ \text { Child labor } & 20 & 24 \\ \text { Strike } & 4 & 5 \\ \text { Others (malaria epidemics...) } & 14 & 17 \\ \text { Total } & 84 & 100\end{array}$

If decrease of students, most important reason for decrease after crisis

Lack of teachers 7

Parents unable to pay for schooling costs

Parents unable to pay for supplies

Parents unable to pay for food $\quad 6 \quad 15$

Children have to work $\quad 7 \quad 17$

Other $\quad 12 \quad 29$

Total $41 \quad 100$

If increase of students, most important reason of increas

\begin{tabular}{lrr} 
Lower transport costs & 2 & 1 \\
More teachers & 7 & 3 \\
Reduction schooling costs & 147 & 71 \\
Other & 51 & 25 \\
Total & 207 & 100 \\
\hline
\end{tabular}

*: only asked for the centers/schools in three provinces (Fianarantsoa, Mahajanga, Antananarivo) 
Table 4: Short model results (fixed effect; three period panel)

\begin{tabular}{|c|c|c|c|c|c|}
\hline \multirow[b]{2}{*}{ Variable } & \multirow[b]{2}{*}{ Unit } & \multicolumn{2}{|c|}{$\log ($ No of visits health center) } & \multicolumn{2}{|c|}{$\log$ (No of students) } \\
\hline & & Coefficient & t-value & Coefficient & t-value \\
\hline Fee & $\log$ (amount) & & & -0.012 & -3.66 \\
\hline Fee & yes $=1$ & -0.169 & -1.77 & & \\
\hline Panel period 2 & Period $2=1$ & -0.170 & -3.09 & -0.055 & -3.67 \\
\hline Panel period 3 & Period $3=1$ & 0.364 & 4.43 & 0.072 & 3.08 \\
\hline Intercept & & 4.278 & 48.25 & 5.300 & 184.90 \\
\hline sigma_u & & 0.902 & & 0.797 & \\
\hline sigma_e & & 0.441 & & 0.174 & \\
\hline rho & & 0.807 & & 0.954 & \\
\hline R-square & within & 0.369 & & 0.259 & \\
\hline & between & 0.000 & & 0.013 & \\
\hline & overall & 0.068 & & 0.005 & \\
\hline Number of observations & & 403 & & 827 & \\
\hline Number of groups & & 139 & & 281 & \\
\hline
\end{tabular}


Table 5: Long model results (fixed effects; three period panel)

\begin{tabular}{|c|c|c|c|c|c|c|c|c|c|}
\hline \multirow[b]{3}{*}{ Variable } & \multirow[b]{3}{*}{ Unit } & \multicolumn{4}{|c|}{$\log$ (No. of visits health center) } & \multicolumn{4}{|c|}{$\log$ (No. of students) } \\
\hline & & \multicolumn{2}{|c|}{ OLS } & \multicolumn{2}{|c|}{ 2SLS } & \multicolumn{2}{|c|}{ OLS } & \multicolumn{2}{|c|}{ 2SLS } \\
\hline & & Coefficient & t-value & Coefficient & t-value & Coefficient & $\mathrm{t}$-value & Coefficient & t-value \\
\hline Availability of working fridge* & yes $=1$ & 0.242 & 2.81 & 0.203 & 0.43 & & & & \\
\hline Fee & yes $=1$ & -0.214 & -2.23 & -0.210 & -1.91 & & & & \\
\hline Number of books* & $\log ($ number $)$ & & & & & 0.003 & 0.59 & 0.046 & 1.45 \\
\hline Fee & $\log ($ amount $)$ & & & & & -0.014 & -3.73 & -0.010 & -2.17 \\
\hline$\%$ of temporary and chronic poor & $\log ($ poor $)$ & -0.288 & -3.44 & -0.286 & -3.20 & -0.001 & -0.04 & -0.032 & -0.93 \\
\hline Transport costs to major city & $\log ($ amount $)$ & 0.173 & 1.64 & 0.165 & 1.19 & -0.034 & -1.06 & -0.032 & -0.94 \\
\hline Panel period 2 & period $2=1$ & -0.262 & -2.70 & -0.263 & -2.68 & -0.028 & -0.99 & -0.027 & -0.86 \\
\hline Panel period 3 & period $3=1$ & 0.268 & 3.02 & 0.273 & 2.60 & 0.068 & 2.37 & -0.028 & -0.36 \\
\hline Intercept & & 3.546 & 3.14 & 3.637 & 2.33 & 5.657 & 16.56 & 5.681 & 15.45 \\
\hline sigma_u & & 0.973 & & 0.971 & & 0.7998 & & 0.789 & \\
\hline sigma_e & & 0.416 & & 0.417 & & 0.1800 & & 0.194 & \\
\hline rho & & 0.845 & & 0.844 & & 0.9518 & & 0.943 & \\
\hline \multirow[t]{3}{*}{ R-square } & within & 0.429 & & 0.428 & & 0.2559 & & 0.140 & \\
\hline & between & 0.004 & & 0.005 & & 0.0013 & & 0.032 & \\
\hline & overall & 0.024 & & 0.024 & & 0.0118 & & 0.033 & \\
\hline $\begin{array}{l}\text { Davidson-MacKinnon endogeneity } \\
\text { error-term instrumental regression }\end{array}$ & & -0.147 & -0.30 & & & -0.044 & -1.48 & & \\
\hline Number of observations & & 369 & & 369 & & 762 & & 762 & \\
\hline Number of groups & & 131 & & 131 & & 267 & & 267 & \\
\hline
\end{tabular}

*: instrumented in 2SLS 
Table 6: Instrumenting regressions (fixed effect; three period panel)

\begin{tabular}{|c|c|c|c|c|c|}
\hline \multirow[b]{2}{*}{ Variable } & \multirow[b]{2}{*}{ Unit } & \multicolumn{2}{|c|}{ Availability fridge (yes=1) } & \multicolumn{2}{|c|}{ Log(No of books) } \\
\hline & & Coefficient & t-value & Coefficient & t-value \\
\hline Fee & yes $=1$ & 0.125 & 1.71 & & \\
\hline Fee & $\log ($ amount $)$ & & & -0.080 & -2.43 \\
\hline$\%$ of temporary and chronic poor & $\log$ (poor) & 0.034 & 0.54 & 0.681 & 2.98 \\
\hline Transport costs to major city & $\log ($ amount $)$ & -0.187 & -2.37 & -0.057 & -0.20 \\
\hline Panel period 2 & period $2=1$ & -0.012 & -0.17 & -0.016 & -0.06 \\
\hline Panel period 3 & period $3=1$ & 0.041 & 0.51 & 1.996 & 6.46 \\
\hline Number of media outlets & $\log$ (number) & 0.213 & 1.21 & 1.078 & 1.64 \\
\hline Number of media outlets*panel 3 & $\log$ (number) & 0.049 & 1.21 & -0.122 & -0.69 \\
\hline Prix of rice & $\log (\mathrm{Fmg} / \mathrm{kg})$ & 0.253 & 2.10 & 0.000 & 0.24 \\
\hline$\%$ of ethnic group of highlands*panel 3 & $\%$ of pop. & & & 0.011 & 3.12 \\
\hline Intercept & & 0.752 & 0.55 & -1.470 & -0.46 \\
\hline sigma_u & & 0.534 & & 1.950 & \\
\hline sigma_e & & 0.314 & & 1.641 & \\
\hline rho & & 0.743 & & 0.585 & \\
\hline \multirow[t]{3}{*}{ R-square } & within & 0.152 & & 0.482 & \\
\hline & between & 0.007 & & 0.002 & \\
\hline & overall & 0.020 & & 0.166 & \\
\hline \multirow[t]{2}{*}{ Test for joint significance of instruments } & & $\mathrm{F}(3,230)$ & Prob $>F$ & $\mathrm{~F}(4,486)$ & Prob $>F$ \\
\hline & & 2.510 & 0.059 & 3.500 & 0.008 \\
\hline Number of observations & & 369 & & 762 & \\
\hline Number of groups & & 131 & & 267 & \\
\hline
\end{tabular}

